\title{
GREEN TOBACCO SICKNESS PADA PETANI TEMBAKAU
}

\author{
Jihan Azita Maharani \\ Fakultas Kedokteran, Universitas Lampung, Jl. Prof. DR. Ir. Sumatri Brojonegoro No.1, Gedong \\ Meneng, Kec. Rajabasa, Kota Bandar Lampung, Lampung, Indonesia 35145 \\ jihan.azita@gmail.com (+6281286756052)
}

\begin{abstract}
ABSTRAK
Green Tobacco Sickness adalah bentuk keracunan nikotin akut yang berisiko dialami oleh petani tembakau. Kondisi ini disebabkan oleh absorpsi nikotin dari tembakau melalui kulit pada saat proses budidaya dan panen tembakau. Green Tobacco Sickness ditandai dengan mual, muntah, sakit kepala, kelemahan otot, dan pusing serta gejala neurologis lainnya. Prevalensi kondisi ini tidak terdokumentasi dengan baik karena kurangnya pengetahuan petani tembakau dan klinisi terkait Green Tobacco Sickness, oleh karena itu penulisan artikel ini dilakukan dengan tujuan membahas etiologi, gejala, diagnosis, pengobatan, serta pengendalian risiko untuk mencegah terjadinya Green Tobacco Sickness pada petani tembakau. Metode analisis yang digunakan yaitu systematic literature review dengan cara menelaah, mengidentifikasi, mengkaji, mengevaluasi, serta menyajikan artikel yang telah disusun dengan merangkum topik dari data sekunder berupa sumber pustaka yang berasal dari jurnal berupa artikel penelitian, guideline, ataupun buku elektronik seperti dari Google Scholar, NCBI, Elsevier, WHO, dan jurnal kesehatan lainnya. Berdasarkan hasil penelusuran, diperoleh 75 artikel yang sesuai kata kunci dalam rentang waktu 1974-2020 dan sebanyak 20 artikel dianggap relevan. Pada hasil dapat disimpulkan bahwa Green Tobacco Sickness adalah penyakit yang berisiko dialami oleh petani tembakau akibat paparan nikotin melalui kontak langsung dan dapat dicegah melalui pencegahan administratif serta penggunaan alat pelindung diri.
\end{abstract}

Kata kunci: green tobacco sickness; nikotin; petani tembakau

\section{GREEN TOBACCO SICKNESS IN TOBACCO FARMERS}

\begin{abstract}
Green Tobacco Sickness is a form of acute nicotine poisoning that tobacco farmers are at risk to experience. This condition caused by the absorption of nicotine from tobacco through the skin during the tobacco cultivation and harvesting process. Green Tobacco Sickness is mostly characterized by nausea, vomiting, headaches, muscle weakness, and dizziness as well as other neurological symptoms. The prevalence of this condition is not well documented due to the lack of knowledge of tobacco farmers and clinicians regarding Green Tobacco Sickness, therefore this article was made to discuss the etiology, symptoms, diagnosis, treatment, and risk control to prevent the occurrence of Green Tobacco Sickness in tobacco farmers. The analytical method used is systematic literature review by examining, identifying, assessing, evaluating, and presenting articles that have been compiled by summarizing topics from secondary data from journals in the form of research articles, guidelines, or electronic books such as from Google Scholar, NCBI, Elsevier, WHO, and other health journals. Based on the search results, 75 articles matched with keywords in the 1974-2020 period were obtained and as many as 20 articles were considered relevant. From the results, it can be concluded that Green Tobacco Sickness is a disease that is at risk of being experienced by tobacco farmers due to exposure to nicotine through direct contact and can be prevented through administrative prevention and the use of personal protective equipment.
\end{abstract}


Keywords: green tobacco sickness; nicotine; tobacco harvesters

\section{PENDAHULUAN}

Nicotiana tabacum atau tembakau merupakan salah satu jenis tanaman komoditas perkebunan utama yang banyak dibudidayakan di Indonesia. Indonesia menempati peringkat kelima sebagai produsen tembakau dunia pada tahun 2012 dengan produksi tembakau sebesar 226.704 ton atau sekitar 3,0\% dari total produksi tembakau dunia. Tiga provinsi penghasil tembakau terbesar di Indonesia yaitu Jawa Timur, Nusa Tenggara Barat (NTB), dan Jawa Tengah. Jumlah petani tembakau juga mengalami peningkatan dari 679,6 ribu orang pada tahun 2010 menjadi 786,2 ribu orang pada tahun 2012. Banyaknya jumlah petani tembakau di Indonesia menyebabkan kesehatan petani tembakau harus mendapat perhatian khusus bagi Pemerintah Indonesia (IAKMI, 2014).

Proses produksi tembakau memiliki dampak kesehatan yang negatif pada pekerja tembakau. Setiap hari, seorang pekerja tembakau yang menanam, mengolah, dan memanen tembakau dapat menyerap nikotin sebanyak jumlah nikotin yang ditemukan dalam 50 batang rokok (Kulik et al., 2017). Saat proses panen, hampir seluruh tubuh petani dapat terkena tanaman tembakau dan berpotensi terpapar nikotin. Proses panen biasanya dilakukan pada pagi hari, yang mana pada saat itu daun tembakau masih basah karena embun sehingga terjadi peningkatan absorpsi nikotin dalam tembakau ke dalam kulit pemanen. Oleh karena itu, petani tembakau berisiko mengalami keracunan nikotin akut yang dikenal sebagai Green Tobacco Sickness (Kulik et al., 2017).
Green Tobacco Sickness (GTS) merupakan salah satu penyakit dalam bidang keselamatan kesehatan kerja yang belum banyak dibahas secara mendalam sebab penyakit tersebut tidak terdokumentasi dengan baik dan kejadiannya sering tidak dilaporkan. Hal tersebut terjadi karena banyak dari mereka yang mengalami Green Tobacco Sickness tidak dapat memahami penyakit mereka maupun penyebab dari gejala yang mereka alami (Fotedar \& Fotedar, 2017). Oleh karena itu, penelitian dan tinjauan literatur mengenai Green Tobacco Sickness penting untuk dilakukan agar dapat meningkatkan pengetahuan dan kesadaran komunitas pekerja tembakau dan klinisi sehingga dapat dilakukan pencegahan dan penatalaksanaan yang tepat.

\section{METODE}

Penelitian ini berjenis tinjauan literatur atau literature review yang disusun dengan langkah analitis merangkum topik dari data sekunder berupa sumber yang diperoleh berdasarkan daftar pustaka yang tertera. Sumber pustaka yang digunakan yaitu berasal dari jurnal berupa artikel penelitian, guideline, ataupun buku elektronik seperti dari Google Scholar, NCBI, Elsevier, WHO, dan jurnal kesehatan lainnya. Kata kunci yang digunakan antara lain green tobacco sickness, nikotin, dan petani tembakau. Berdasarkan hasil penelusuran, diperoleh 75 artikel yang sesuai kata kunci dalam rentang waktu 1974-2020 dan sebanyak 21 artikel dianggap relevan. Metode analisis yang digunakan adalah systematic literature review dengan cara menelaah, mengidentifikasi, mengkaji, mengevaluasi, serta menyajikannya. Sebelum proses penyajian, dilakukan peng- 
gabungan, pengevaluasian, dan pembandingan hasil yang disajikan artikel untuk selanjutnya dapat dilakukan penarikan kesimpulan yang tepat.

\section{HASIL}

Green Tobacco Sickness (GTS) atau penyakit tembakau hijau merupakan penyakit akibat bahaya potensial kimia, yaitu nikotin, yang berisiko terjadi pada petani dan pekerja tembakau. Nikotin adalah senyawa alkaloid dalam tembakau yang memiliki berat molekul rendah dengan sifat kelarutan dalam lemak dan air yang baik sehingga dapat dengan mudah diserap oleh kulit (Reddy \& Ashok, 2019). Nikotin merupakan stimulan adiktif sistem saraf pusat (SSP) yang dapat menyebabkan stimulasi ganglionik dalam dosis rendah atau penyumbatan ganglionik dalam dosis tinggi. Nikotin bertindak sebagai agonis pada reseptor kolinergik nikotinik di ganglia otonom, neuromuscular junction, medula adrenal, dan otak. Aktivitas stimulasi SSP oleh nikotin dapat dimediasi melalui pelepasan beberapa neurotransmiter, termasuk asetilkolin, beta-endorphin, dopamin, norepinefrin, serotonin, dan ACTH. Akibatnya, terjadi vasokonstriksi perifer, takikardia, dan tekanan darah tinggi yang dapat diamati pada pasien yang terpapar nikotin (National Center for Biotechnology Information., n.d.).

Green Tobacco Sickness adalah salah satu penyakit yang kurang terdokumentasi dengan baik, sehingga tidak dapat dipastikan dengan jelas berapa angka kejadiannya di seluruh dunia per tahun. Pada penelitian di Bantul, Indonesia, didapatkan 7 dari 10 petani tembakau mengalami Green Tobacco Sickness (Kau \& Kusnanto, 2017). Pada penelitian yang dilakukan di Brazil, didapatkan sebanyak 82,3\% responden mengalami gejala Green Tobacco Sickness seperti pusing, sakit kepala, lemas, serta mual muntah (Oliveira et al., 2010). Sedangkan pada penelitian di Korea Selatan didapatkan prevalensi GTS sebesar 37,5\% dan secara signifikan lebih tinggi pada wanita dibandingkan pada pria $(55,0 \%$ vs $20,0 \%, p<0,01)$. Insiden GTS menurut jumlah hari kerja adalah 3.4 kejadian / 100 orang hari (Park et al., 2018). Menurut Fotedar \& Fotedar (2017), prevalensi GTS secara global berkisar sekitar 8,2 hingga $47 \%$. Untuk dapat mengurangi risiko terjadinya Green Tobacco Sickness pada petani tembakau, perlu dilakukan pengendalian risiko yang dilakukan secara sistematis, baik secara administrative maupun dengan cara penggunaan alat pelindung diri.

\section{PEMBAHASAN \\ Etiologi}

Green Tobacco Sickness adalah bentuk keracunan nikotin akut yang mempengaruhi pekerja tembakau yang memiliki kontak langsung dengan tanaman tembakau selama budidaya dan panen (Reddy \& Ashok, 2019). Sebagian besar daun tersebut dikumpulkan dan digendong sesuai kemampuan petani. Proses panen secara manual menggunakan tangan tetap menjadi metode yang lebih sering digunakan oleh petani karena petani dapat sekaligus memilih daun tembakau yang matang dan siap dipanen. Proses panen menggunakan mesin jarang dilakukan oleh petani tembakau karena biaya yang mahal dan daun yang dipetik memiliki kualitas yang lebih rendah dibandingkan dengan daun yang dipetik menggunakan tangan (Schmitt \& Schmitt, 2007). Proses panen menggunakan tangan dapat menyebabkan abrasi pada kulit tangan yang mana dapat meningkatkan risiko 
terjadinya Green Tobacco Sickness pada petani tembakau (McBride et al., 1998).

Keracunan nikotin dilaporkan pada pekerja tembakau dan juga pada orang yang secara sengaja atau tidak sengaja tertelan tembakau atau larutan yang mengandung nikotin. Risiko keracunan nikotin meningkat ketika nikotin yang terkandung dalam daun tembakau bercampur dengan hujan, embun, atau keringat, memungkinkan nikotin masuk ke kulit dan masuk ke aliran darah dengan lebih mudah. Pekerja dapat mengalami gejala Green Tobacco Sickness saat bekerja atau beberapa jam setelah hari kerja berakhir (NIOSH, 2015).

\section{Gejala}

Green Tobacco Sickness sebagian besar ditandai oleh mual, muntah, sakit kepala, kelemahan otot, dan pusing. Gejala mual dan muntah pada pasien Green Tobacco Sickness dimediasi oleh aksi langsung nikotin pada zona pemicu kemoreseptor emetik di medula oblongata yang menyebabkan refleks muntah (Svenson, 1987). Gejala neurologis lainnya yaitu pucat, pusing, peningkatan keringat, menggigil, sakit perut, diare, peningkatan air liur (salivasi), dan kelemahan. Nikotin merangsang saraf sensorik dari usus dan saraf parasimpatis di saluran pencernaan, yang menyebabkan peningkatan sekresi dan motilitas gastrointestinal secara keseluruhan sehingga diare dapat menjadi salah satu pada pasien Green Tobacco Sickness (Taylor, 1996). Gejala yang timbul tergantung pada seberapa besar pajanan nikotin pada tubuh petani dan berdurasi singkat. Gejala-gejala lain seperti batuk dengan atau tanpa dahak dan sesak napas dianggap sebagai keluhan pernapasan, dan sesekali penurunan tekanan darah atau detak jantung. Rata- rata lama penyakit, dengan pengobatan, adalah antara 1 dan 3 hari (median $=2,4$ hari). Gejala akan reda apabila petani mengurangi paparan nikotin secara langsung (Fotedar \& Fotedar, 2017).

\section{Diagnosis dan Pengobatan}

Diagnosis klinis Green Tobacco Sickness dapat ditegakkan berdasarkan gejala yang timbul serta riwayat kontak dengan tembakau, baik dalam proses panen maupun dalam proses produksi produk tembakau. Gejala yang dialami pasien dengan Green Tobacco Sickness dapat menyerupai pasien yang terpapar oleh pestisida golongan organofosfat atau kelelahan akibat panas yang berlebihan (heat exhaustion). Selain itu, gejala Green Tobacco Sickness juga dapat menyerupai gejala pada pasien yang mengalami keracunan nikotin (biasa terjadi pada perokok pemula), oleh karena itu penting bagi klinisi untuk mengetahui riwayat paparan nikotin pada pasien secara jelas untuk mencegah diagnosis yang kurang tepat. Beberapa gejala keracunan pestisida golongan organofosfat seperti lakrimasi, edema paru, dan miosis tidak ditemukan pada pasien Green Tobacco Sickness sehingga gejala tersebut dapat menjadi pembeda antara pasien Green Tobacco Sickness dengan pasien keracunan pestisida organofosfat. Waktu terjadinya gejala juga penting untuk diperhatikan oleh klinisi untuk dapat membedakan pasien Green Tobacco Sickness dengan pasien keracunan pestisida. Penggunaan pestisida oleh petani tembakau biasanya akan berakhir beberapa minggu sebelum musim panen, sedangkan Green Tobacco Sickness banyak terjadi saat musim panen berlangsung (Hipke, 1993).

Tembakau biasanya dipanen selama cuaca panas, tetapi Green Tobacco Sickness juga dapat timbul pada kondisi 
sejuk, oleh karena itu diagnosis heat exhaustion dapat disingkirkan pada kondisi tersebut. Median onset untuk Green Tobacco Sickness yaitu 10 jam, biasanya pasien mengeluhkan gejala setelah pulang ke rumah. Hal ini dapat menjadi petunjuk untuk membedakan pasien Green Tobacco Sickness dengan pasien heat exhaustion yang mengalami keluhan pada saat terpapar panas di lokasi perkebunan (Boylan et al., 1993).

Untuk menegakkan diagnosis pasti, dapat juga dilakukan pemeriksaan kadar nikotin (half life = 3-4 jam) atau cotinine (metabolit nikotin dengan waktu paruh 36 jam) dalam darah atau urin. Cotinine juga dapat dideteksi dalam spesimen saliva (Ballard et al., 1995). Pada penelitian di Kabupaten Jember, Indonesia, ditemukan hasil bahwa sebanyak $79,2 \%$ petani tembakau memiliki rata-rata kadar kotinin dalam darah sebesar 13,64 $\mathrm{mg} / \mathrm{ml}$.. Angka tersebut tergolong tinggi karena pada normalnya kotinin dalam darah manusia berjumlah tidak lebih besar dari $2 \mathrm{mg} / \mathrm{ml}$. Pada penelitian tersebut juga didapatkan kesimpulan bahwa terdapat hubungan antara gejala Green Tobacco Sickness yaitu mual dan sesak napas dengan kadar kotinin pada petani tembakau (Rokhmah, 2015).

Green Tobacco Sickness bersifat selflimiting, yaitu penyakit yang dapat sembuh sendiri dengan durasi sakit yang tidak lama, oleh karena itu pengobatan tidak selalu diperlukan. Pada penelitian yang dilaksanakan di Temanggung, sebagian besar responden yang mengalami Green Tobacco Sickness memilih untuk tidak pergi ke pelayanan kesehatan (Permatasari et al., 2020). Meskipun durasi Green Tobacco Sickness relatif singkat, Green Tobacco Sickness dapat terasa sangat mengganggu selama keluhan berlangsung sehingga dapat menurunkan produktivitas petani tembakau (Achalli et al., 2012). Saran paling umum yang dapat dilakukan setelah gejala muncul adalah hindari peningkatan kontak dengan tembakau. Hal ini dapat dilakukan dengan berhenti bekerja sesaat, berganti pakaian, mandi, dan istirahat. Pekerja yang terpajan juga sebaiknya meningkatkan asupan cairan dan dapat diresepkan untuk mengonsumsi H1 blocker seperti dimenhydrinate (Dramamine). Jika muncul gejala serius, dokter dapat memberikan hidrasi intravena, antiemetik, dan H1 blocker (dimenhidrin) (Hipke, 1993).

\section{Pengendalian Risiko}

Green Tobacco Sickness sering terjadi pada petani akibat tidak menggunakan Alat Pelindung Diri (APD) yang tepat pada proses bercocok tanam tembakau (Fotedar \& Fotedar, 2017). Gejala Green Tobacco Sickness juga berhubungan dengan perilaku personal hygiene petani tembakau (Rokhmah, 2015). Menurut hierarki pengendalian risiko, terdapat lima metode yang dapat dilakukan untuk melakukan pengendalian risiko, yaitu eliminasi, substitusi, rekayasa teknik, pengendalian administratif, dan penggunaan alat pelindung diri. Metode pengendalian risiko yang dapat dilakukan untuk mengendalikan risiko dari bahaya potensial nikotin yaitu dengan menggunakan metode pengendalian administratif dan penggunaan alat pelindung diri (NIOSH, 2015).

Beberapa hal yang menjadi faktor risiko terjadinya Green Tobacco Sickness pada petani tembakau yaitu tingkat pendidikan, durasi kerja, masa kerja, dan penggunaan alat pelindung diri . Oleh karena itu, pada metode 
pengendalian administratif, pemerintah atau pihak yang mempekerjakan petani harus memberikan petani informasi dan pelatihan tentang bahaya nikotin, pencegahan Green Tobacco Sickness, dan penggunaan alat pelindung diri yang tepat serta mengatur durasi kerja sebelum membiarkan petani bekerja menangani daun tembakau (Kau \& Kusnanto, 2017). Hasil penelitian menemukan bahwa terdapat hubungan yang signifikan antara penggunaan APD dengan pengetahuan petani mengenai Green Tobacco Sickness. Oleh karena itu, pengetahuan petani tembakau mengenai Green Tobacco Sickness harus ditingkatkan (Andriany et al., 2019). Pemberian informasi dan pelatihan perlu dilakukan secara efektif dalam bahasa dan kosa kata yang dapat dipahami oleh pekerja (Achalli et al., 2012).

Pekerja yang baru menangani dan memanen tembakau berisiko lebih tinggi untuk mengalami Green Tobacco Sickness. Beberapa hal yang menyebabkan meningkatnya faktor risiko tersebut, yaitu toleransi tubuh pekerja baru yang lebih rendah terhadap paparan nikotin dan kurangnya pengetahuan pekerja baru terkait Green Tobacco Sickness serta alat pelindung diri sebagai metode pencegahan Green Tobacco Sickness. Petani tembakau juga tidak disarankan melakukan panen pada saat hujan dan sebaiknya memulai panen setelah embun pada daun-daun tembakau telah menguap (Gehlbach et al., 1974). Selain itu, kurangnya pengetahuan petani terkait rentannya pekerja anak dan remaja terhadap paparan nikotin serta efek kesehatan yang dapat timbul lebih berat pada golongan tersebut dapat meningkatkan risiko terjadinya Green Tobacco Sickness pada pekerja anak dan remaja. Oleh karena itu, metode pengendalian risiko secara administratif ini perlu dilaksanakan dengan baik dan efektif (NIOSH, 2015).

Metode selanjutnya dalam pengendalian risiko paparan nikotin yaitu penggunaan alat pelindung diri (APD). Petani disarankan untuk menggunakan sarung tangan, kemeja lengan panjang, celana panjang dan pakaian tahan air untuk mencegah paparan nikotin dari daun tembakau (McBride et al., 1998). Pemerintah atau orang yang mempekerjakan petani tembakau harus melatih petani tentang cara merawat dan membersihkan pakaian mereka untuk memastikan bahwa pakaian tersebut mampu melindungi mereka dari paparan nikotin (NIOSH, 2015).

\section{Menurut National Institute for} Occupational Safety and Health Publication (2015), terdapat beberapa hal yang perlu diperhatikan dalam penggunaan alat pelindung diri pada petani tembakau. Penggunaan sarung tangan bertujuan untuk mencegah penyerapan nikotin melalui kulit tangan saat memegang dan memetik daun tembakau. Sarung tangan dapat melindungi kulit dari paparan nikotin secara efektif apabila dalam keadaan kering, sehingga perlu dijaga tetap kering dan diganti dengan sarung tangan kering apabila sarung tangan basah. Dianjurkan untuk menggunakan baju berlengan Panjang serta celana Panjang untuk memberikan perlindungan bagi tubuh pekerja dari paparan nikotin pada tembakau pada bagian ekstremitas dan badan. Pakaian juga perlu dijaga tetap kering dan diganti apabila basah, baik karena air hujan, embun, maupun keringat, karena pakaian yang basah dapat meningkatkan risiko penyerapan nikotin melalui kulit. Pakaian basah dapat diganti menjadi pakaian kering beberapa kali sesuai 
kebutuhan sepanjang hari kerja. Selain itu, petani dapat juga menggunakan pakaian tahan air untuk menjaga kulit dari kontak langsung dengan air hujan atau embun pada daun tembakau yang mengandung nikotin. Petani dianjurkan mengonsumsi lebih banyak air, beristirahat secara berkala, dan bernaung di tempat yang teduh saat menggunakan pakaian tahan air pada cuaca panas agar tidak mengalami dehidrasi dan heat stress (NIOSH, 2015).

Selain menggunakan APD, petani juga dianjurkan untuk menjaga personal hygiene dengan cuci tangan dan mandi setelah selesai bekerja. Mandi dengan sabun dan air segera setelah bekerja dianjurkan untuk mengurangi paparan nikotin. Mandi dengan sabun dapat mengurangi jumlah nikotin yang ada di kulit hingga 96\%. Pemerintah atau orang yang mempekerjakan petani tembakau harus menyediakan fasilitas cuci tangan untuk petani dan pekerja lainnya agar pekerja dapat melakukan cuci tangan dengan sabun dan air bersih yang mengalir untuk mengurangi risiko paparan nikotin (NIOSH, 2015).

\section{SIMPULAN}

Green tobacco sickness (GTS) adalah suatu risiko kesehatan bagi petani tembakau akibat terpapar nikotin pada tembakau secara langsung melcddwalui absorpsi kulit. Gejala Green Tobacco Sickness antara lain yaitu mual, muntah, sakit kepala, kelemahan otot, dan pusing serta gejala neurologis lain seperti pucat, pusing, peningkatan keringat, menggigil, sakit perut, diare, peningkatan air liur (salivasi), dan kelemahan otot. Selain dari anamnesis dan temuan pemeriksaan fisik yang sesuai dengan gejala, untuk memastikan diagnosis GTS dapat dilakukan pemeriksaan kadar nikotin atau cotinine dalam darah atau urin. GTS adalah suatu penyakit yang bersifat selflimiting atau dapat sembuh sendiri dengan durasi sakit yang tidak lama, oleh karena itu pengobatan tidak selalu diperlukan. Tindakan pertama yang perlu dilakukan dalam mengatasi GTS yaitu menjauhkan penderita dari paparan. Dokter dapat pula meresepkan H1 blocker seperti dimenhydrinate (Dramamine) dan bila muncul gejala serius dapat diberikan hidrasi intravena, anti-emetik, dan H1 blocker (dimenhidrin). Edukasi komunitas petani tembakau mengenai Green Tobacco Sickness dan penggunaan alat pelindung diri perlu dilakukan sebagai bentuk pengendalian risiko terjadinya Green Tobacco Sickness pada petani tembakau. Klinisi juga perlu meningkatkan pengetahuan mengenai Green Tobacco Sickness agar dapat mendiagnosis dan menangani penyakit ini dengan tepat.

\section{DAFTAR PUSTAKA}

Achalli, S., Shetty, S. R., \& Babu, S. G. (2012). The Green Hazards: A Meta-Analysis of Green Tobacco Sickness. International Journal of Occupational Safety and Health, 2(1), 11-14. https://doi.org/10.3126/ijosh.v2i1.4 963

Andriany, M., Cahyo, K., \& Kusumawati, A. (2019). Relationship of Knowledge and Perception of Work Health Problems and Behavior of Use of Tobacco Protective Tools. Jurnal Ilmu Keperawatan Komunitas, 2(1), 1-7.

Ballard, T., Ehlers, J., Freund, E., Auslander, M., Brandt, V., \& Halperin, W. (1995). Green tobacco sickness: occupational nicotine poisoning in tobacco 
workers. Arch Environ Health, 50(5), 384-389. https://doi.org/10.1080/00039896.1 995.9935972.

Boylan, B., Brandt, V., Muehlbauer, J., \& Auslander, M. (1993). Green tobacco sickness in tobacco harvesters-Kentucky, 1992. MMWR, 42(13), 237-240.

Fotedar, S., \& Fotedar, V. (2017). Green Tobacco Sickness: A Brief Review. Indian Journal of Occupational and Environmental Medicine, 21(3), 101-104. https://doi.org/10.4103/ijoem

Gehlbach, S., Williams, W., Perry, L., \& Woodall, J. (1974). Greentobacco sickness: an illness of tobacco harvesters. JAMA, 229(14), 1880-1883.

Hipke, M. (1993). Green Tobacco Sickness. Southern Med J, 86, 989-992.

IAKMI. (2014). Buku Bunga Rampai Fakta Tembakau dan Permasalahannya (V). Tobacco Control Support Center - IAKMI.

Kau, A. D., \& Kusnanto, H. (2017). Prevalensi Kasus Green Tobacco Sickness pada Pekerja Petani Tembakau di Bantul. Berita Kedokteran Masyarakat, 33(6), 311-316.

Kulik, M. C., Bialous, S. A., Munthali, S., \& Max, W. (2017). Tobacco growing and the sustainable development goals. Bulletin of the World Health Organization, 95(5), 362-367.

https://doi.org/10.2471/BLT.16.17 5596

McBride, J. S., Altman, D. G., Klein,
M., \& Wain, W. (1998). Green Tobacco Sickness. Tobacco Control, 7, 294-298.

National Center for Biotechnology Information. (n.d.). Nicotine. PubChem Database.

NIOSH. (2015). Recommended Practices: Green Tobacco Sickness. National Institute for Occupational Safety and Health Publication, 6742, 1-5.

Oliveira, P. P. V. de, Sihler, C. B., Moura, L. de, \& Malta, D. C. (2010). First reported outbreak of green tobacco sickness in Brazil 2010; 26: 2263-2269. Cad. Saúde Pública, 26(12), 2263-2269.

Park, S.-J., Lim, H.-S., Lee, K., \& Yoo, S.-J. (2018). Green Tobacco Sickness Among Tobacco Harvesters in a Korean Village. Saf Health Work, 9(1), 71-74. https://doi.org/10.1016/j.shaw.201 7.06.007

Permatasari, V., Musthofa, S. B., \& Prabamurti, P. N. (2020). Faktor yang Berhubungan Antara Perilaku Pencarian Pengobatan Gejala Green Tobacco Sickness (GTS) dengan Petani Tembakau di Kecamatan Bansari, Kabupaten Temanggung. Jurnal Kesehatan Masyarakat, $\quad 8(2), \quad 82-88$. http://ejournal3.undip.ac.id/index.p $\mathrm{hp} / \mathrm{jkm}$

Reddy, M., \& Ashok, N. (2019). Green Tobacco Sickness - A Brief Review. Austin Journal of Dentistry, 6(2), 2-4.

Rokhmah, D. (2015). Insidens dan Perilaku Pencarian Penyembuhan (Health Seeking Behaviour) Green Tobacco Sickness (GTS) pada 
Petani Tembakau. 26, 1-14. http://repository.unej.ac.id/handle/ $123456789 / 63276$

Schmitt, N. M., \& Schmitt, J. (2007). Health risks in tobacco farm workers - a review of the literature. J Public Health, 15, $255-264$.

https://doi.org/10.1007/s10389-

007-0122-4

Svenson, C. (1987). Clinical pharmacokinetics of nicotine. Clin Pharmacokinet, 12, 30-40.

Taylor, P. (1996). Agents acting at the neuromuscular junction and autonomic ganglia. In: Hardman JG, Gilman AG, Limbird LE, eds. In Goodman \& Gilman's the pharmacological basis of therapeutics. McGraw-Hill. 
Jurnal Penelitian Perawat Profesional, Volume 3 No 1 Hal 107 - 116, Februari 2021 Global Health Science Group 